\title{
UNA POÉTICA SUBLITERARIA EN EL SIGLO XVII
}

\section{A LOW LITERATURE POETICS IN THE SEVENTEENTH CENTURY}

\author{
Miguel Ángel GARRIDO GALLARDO
}

\author{
$\mathrm{CCHS} / \mathrm{CSIC}$ \\ miguelangel.garrido@cchs.csic.es
}

Resumen: El Ejemplar poético (1606), de Juan de la Cueva, forma parte del conjunto de poéticas que a finales del siglo XVI y principios del XVII configuraron un segmento muy considerable del humanismo español en general y de la teoría del teatro en particular. No siendo una de las más importantes, tiene, sin embargo, un interés especial por cuanto proporciona las bases de una teoría explícita de la subliteratura. No se trata de ofrecer otras formas actualizadas de mímesis que puedan ser tan válidas como las clásicas ni tampoco de «ceder» ante las exigencias del público ignorante, sino de instaurar una posibilidad de lectura y entretenimiento distinta.

Abstract: Juan de la Cueva's El ejemplar poético (1606) forms a part of a series of Spanish humanistic treatises which puts theatre into a dialogue with other genres popular during the sixteenth and seventeenth centuries. Although it is not one of the most important treatises of the era, it does merit special attention due to the fact that it presents an explicit theory of «low literature» in Spain. It does not attempt to develop new theories of mimesis, in 
line with other humanistic thinkers, nor does it conceive of theater as a genre which cedes to the needs of its audience, rather, this treatise offers a new way to read and enjoy literature.

Palabras clave: Poética renacentista. Juan de la Cueva. Retórica. Semiótica literaria. Subliteratura.

Key Words: Renaissance Poetics. Juan de la Cueva. Rhetoric. Literary Semiotics. Low literature.

\section{PREÁmbUlo}

Podemos decir que a principios del siglo XVII el panorama de las ciencias del discurso estaba ya en España enteramente abierto a una producción genuina, por de pronto, encontramos los textos en lengua romance. En realidad, el siglo XVI continúa la cultura grecolatina que se especifica en la Poética de Aristóteles y de Horacio, disciplina de la creación o recreación hecha con palabras; la Retórica de Quintiliano, disciplina que enseña a llevar a cabo un discurso eficaz y la Métrica («arte del verso») que se especializa en el estudio de las matrices rítmicas en las que puede codificarse el discurso, lo cual suele estar relacionado con la poética, aunque ya advirtiera Aristóteles por dos veces que si bien someterse a una matriz rítmica era síntoma de creación artística, el procedimiento no basta, ya que también se puede metrificar un tratado de ciencias naturales y no por eso podría ser considerado creación («literatura», usando el anacronismo).

Poética, Retórica y Métrica, como denominaciones, mantendrán una cierta confusión inevitable, derivada de la indefinición de fronteras. Las técnicas que la Retórica prescribe para hacer un discurso llamativo con vistas a la persuasión han de ser en parte las mismas que la Poética lleva a cabo con vistas a la fruición. Y ya hemos dicho que la metrificación cabe tanto en los textos poéticos como en los retóricos. La disciplina semiótica que aborda el estudio de la producción del sentido creador (artístico, lo llamaríamos hoy), se llama poética, pero la disciplina que estudia la composición del discurso artístico puede llamarse retórica, por lo que hemos dicho, pero también poética, por su objeto. Por eso, las dudas sobre el nombre de la obra que vamos a estudiar y que manifiesta su autor, Juan de la Cueva, que termina por llamarla Ejemplar poético, están más que justificadas. 
La teoría del discurso de la época está muy bien tratada de modo panorámico en la Historia de las ideas estética en España (pp. 683-837) y otras de D. Marcelino Menéndez Pelayo (1983, 1985, 1990) y, como he señalado reiteradamente, se ha continuado investigando minuciosamente a partir de la segunda mitad del siglo XX. Yo mismo he dirigido la obra colectiva Retóricas españolas del siglo XVI escritas en latín (Garrido Gallardo, ed., 1994), que estudia y anota 15 importantes retóricas, empezando por la de Antonio de Nebrija, que edité y anoté personalmente. La significación de este corpus ha sido ponderada antes y después, entre otros, por mi grupo (Garrido Gallardo et alii, 1998, 2007). Y el trabajo prosigue. En cuanto a las poéticas, véanse, por ejemplo, los títulos de Antonio Vilanova (1949) o de Antonio García Berrio (1980), sin olvidar panoramas más generales como el de Bernard Weinberg (1961, 2003), Spingarn (1963) o Norton (1999).

Esta es, pues, la situación del corpus tradicional escrito durante el siglo XVI en latín como lingua franca académica, pero que a comienzos del siglo XVII se había abierto ya a la lengua castellana con la publicación del modelo latino adaptado al español, que se sigue en la Retórica en lengua castellana de Miguel de Salinas (1541) y la edición de la primera retórica propiamente castellana, la Elocuencia española en arte (1604) de Bartolomé Jiménez Patón. Sin contar con los textos de poética, que se evocan explícitamente en la obra objeto de nuestra atención (Cf., p.e., Sánchez de Lima, 1580; Díaz Rengifo, 1592).

Con estos antecedentes nos enfrentamos al Ejemplar poético (1606) de Juan de la Cueva, autor que ya ha conocido estudios en el pasado (Walberg,1961), pero al que nos ha atraído la atención ahora la reciente tesis de Tim Fujioka (2010) que ha cotejado esta obra con la más importante Philosophia antigua poetica (1595) de Alonso López Pinciano (Cf. Shephard, 1970), El trabajo ratifica la impresión de D. Marcelino Menéndez Pelayo acerca de la poca entidad que hay que atribuir a la obra de Juan de la Cueva. Sin embargo, en su análisis minucioso, topamos, como veremos, con una importante sorpresa.

La obra está constituida por tres epístolas en tercetos encadenados al modo utilizado por Miguel de Cervantes en El Viaje del Parnaso. Tratan, de modo bastante desordenado, casi todas las cuestiones de poética, retórica y métrica castellana que podemos encontrar en los manuales de la época (Cfr., p.e., Prieto, 1984; Smith, 1985; Terry, 1993) y termina, al final de la tercera epístola, con una teoría de la comedia nueva española, cuestión candente en el momento y que, por su cercanía, se puede considerar antecedente del Arte Nuevo de Hacer Comedias (1609) de Lope de Vega. 
La primera epístola comienza, como es de rigor sobre la cuestión de si el poeta nace o se hace, o sea, sobre la influencia de ingenium y ars en la creación. En este contexto, apunta Juan de la Cueva un interés especial por el equilibrio:

Sobre el ingenio y el arte disputaron

Palas y el fiero hijo de la Muerte

A quien del cielo por odioso echaron.

La sabia diosa, su razón convierte

En decir que el ingenio sin el arte

Es ingenio sin arte cuando acierte.

(I, 1-6)

Las reglas son las que garantizan la calidad formal. Puede haber poesía sin reglas, pero será pura casualidad. Las reglas son medida del ingenio. Aunque también hay que decir que reglas sin ingenio producen composiciones de vano artificio. Pero las reglas no son en absoluto desdeñables: cuanto menos ingenio, más necesidad de entrenamiento tiene el que escribe para hacerlo bien y, con todo, no conseguirá una producción de auténtica calidad. Esto es lo que observa Juan de la Cueva ya desde el principio. O sea, el ten con ten:

De estas dos causas seguiré la parte

por do el ingenio inspira, el arte adiestra

Sin que de su propósito me aparte.

(I,. 7-9)

\section{CANON LATINO}

Al final de la primera epístola se incluye un canon de lo excelente según el Humanismo. El listado «demuestra» el conocimiento que tiene Juan de la Cueva de la «alta cultura» del momento, que parece obligatorio exhibir en obras como esta, según comprobaremos no mucho después en el ya citado Arte Nuevo de Hacer Comedias de Lope de Vega.

A Séneca dejo el lloroso oficio

de la tragedia, a Plauto y a Cecilio

de la vulgar comedia el ejercicio.

(I, 505-507) 
Comienza la relación con Séneca, referencia indispensable, por sus orígenes cordobeses, cabeza de una presunta literatura hispano latina y personaje de prestigio moral. Aparece como autor trágico, aunque hoy nos suene quizás más su condición de moralista y filósofo. En el canon de entonces figuraban diez tragedias que escribió especialmente en el período de la educación a Nerón. De ellas, Hércules Oetano es dudosa y Octavia es apócrifa. He aquí la lista: Hércules furioso, las Troyanas, Medea, Hipólito, Edipo, Agamenón, Tiestes, Hércules Oetano, las Fenicias, Fedra y Octavia.

«El lloroso oficio de la tragedia» a que se refiere Juan de la Cueva marca, pues, la dimensión de contenido del género que presupone los dolores y espantos del héroe que se enfrenta a su destino.

Plauto fue el comediógrafo latino de mayor renombre en el Renacimiento. Autor de comedias palliatae adaptadas del griego. La popularidad de que disfrutó en vida seguía viva en la cultura del Renacimiento. A Plauto se le atribuyeron muchas obras, pero Varrón en el siglo primero fijó el elenco en veintiuna. Con un lenguaje coloquial que no rehúye la grosería e incluso la obscenidad, no dejan de ser una muestra rica y variada del latín de su época. De estilo original por su léxico y sus registros estilísticos., hay quien ha querido ver en determinados personajes suyos un antecedente del «gracioso» de la comedia del Siglo de Oro. Comedias de Plauto son Anfitrión, Asinaria, Aulularia, los Cautivos, Casina, Cistellaria, el Gorgojo, Epiducus, Menaechmi, el Mercader, el Soldado fanfarrón, el Aparecido, Poenunus, el Trapalón, Persa, Rubens, Estichus, Trinummus, Truculento y Vidularia.

En fin, inevitable sin duda en este canon, Juan de la Cueva llama a esta producción «vulgar comedia», no sé si pensando en el teatro griego como modelo máximo.

El siguiente no es Terencio (que brilla en el Ejemplar por su ausencia), sino Cecilio Estacio, autor cómico a quien Volcacio Sedígito sitúa como el primer poeta cómico, Varrón le atribuye pathos y maestría en la composición de las tramas, Horacio lo compara con Terencio, Quintiliano, sin embargo, hace una alusión más bien despectiva a él y Cicerón lo considera en todo caso explícitamente inferior a Terencio. Fragmentos de sus obras han sido conservados por Aulo Gelio que cita varios pasajes de Ploczum (collar) junto con el original griego de Menandro. Cicerón alude a la comedia Epicleros y cita dos líneas.

Juan de la Cueva ha exhibido una erudición de poliantea ciertamente muy limitada, pero suficiente para hacer creer que el autor del Ejemplar conoce 
los autores latinos cuya autoridad no se discute. Sin duda, las presuposiciones que están detrás de estas simples menciones son las que conocemos en toda la poética clásica.

A continuación, menciones igualmente sucintas y convencionales a la poesía épica:

Cantar las armas remitió a Virgilio, al de Ascra de dioses y labores, a quien dio Apolo celestial auxilio.

(I, 508-510)

En la épica se comienza por Virgilio y Hesíodo, considerado éste el más antiguo de los poetas griegos después de Homero, natural de Ascra, cerca de Tebas, nacido hacia la segunda mitad del siglo VIII a.C. o la primera del siglo VII. Es autor, como se sabe, de los Trabajos y los días y de la Teogonía que explica el origen del universo y la genealogía de los dioses. La obra de Hesíodo se había convertido en una referencia fundamental de la cultura griega en el Renacimiento, gracias a la lectura moral y práctica que se hizo de sus textos. El Ejemplar poético no puede prescindir de este autor al que se le reconoce un especial valor («dio Apolo celestial auxilio») y cuya mención mediante la antonomasia el de Ascra, iguala convención con la del Estagirita, que ha cubierto y cubre por los siglos de los siglos la mención de Aristóteles.

Virgilio es la referencia absoluta de la épica («cantar las armas»). El poeta romano, autor de la Eneida, ha sido ejemplo fundamental de poesía épica a lo largo de la literatura occidental. Los doce libros que relatan las aventuras del troyano Eneas desde su huida de Troya hasta su victoria militar en Italia proporcionan a Roma una épica de los comienzos y la vincula con la tradición griega. Eneas lleva a su padre Anquises sobre sus hombros y a su hijo Ascanio de la mano. Éste funda Alba longa, ciudad que será más tarde Roma. Los romanos venían a ser descendientes de Ascanio y, por lo tanto, de Eneas mismo. Virgilio fue considerado poeta ejemplar tanto en su época como en la Edad Media y el Renacimiento. La Eneida fue sometida a una hermenéutica alegórica que llegó a atribuirle tintes proféticos. El esfuerzo renacentista por conectar cultura clásica y cristianismo encontró en la Eneida de Virgilio un aliado fundamental. Hay que recordar que Dante Alighieri pone a Virgilio como guía a través del infierno y del purgatorio en la Divina Comedia.

Para la lírica, Juan de la Cueva evoca a Horacio y a Tibulo. Sin duda Horacio es el principal poeta lírico y satírico del latín clásico, aunque destaque 
de manera incomparable su producción lírica, razón por la cual el Ejemplar poético lo especializa en este registro. Las odas de Horacio son obras cumbres de la lírica latina, imitan los metros líricos griegos, sobre todo de Alceo, Safo y Anacreonte. Abarcan variados temas: la alabanza de Augusto, el elogio de la amistad, el gusto por el campo y la naturaleza, y otras cuestiones morales y filosóficas. Hay tópicos como la receta de la aurea mediocritas para ser feliz, o el carpe diem como exhortación para aprovechar el instante presente, que tendrán una gran fortuna en la historia de la literatura universal, como atestigua la obra de E.R. Curtius, Literatura europea y Edad media latina (1948), Ronsard, Petrarca o Garcilaso se encuentran muchas veces en la estela de las reflexiones horacianas. Se puede decir que Horacio sigue tan vivo hoy como en el momento en que a Juan de la Cueva le sirve de referencia antonomástica. No hace falta recordar la paráfrasis de Fray Luis ni los testimonios de Menéndez Pelayo en su Horacio en España.

Llama la atención que el Ejemplar poético no cite aquí a Ovidio. Es Tibulo el elegido. Los temas preferentes de Tibulo son el amor, la amistad, la muerte y el rechazo de la guerra, del comercio y de la riqueza. Amante de cultivar la vida campesina sencilla y tranquila, al lado de la amada, está próximo a las Bucólicas de Virgilio. La cita también es obligada.

Tras el drama, la épica y la lírica, queda la sátira. Y, pasada por alto la producción de Horacio al respecto, hay que acudir necesariamente a Juvenal. Décimo Junio Juvenal, autor de dieciséis sátiras, es el creador de este género en Roma, en una tradición que incluye, como hemos dicho, a Horacio y también a Persio. Las sátiras de Juvenal suponen una acerba crítica de la Roma de su tiempo y es seguramente por esta razón por la que han subsistido en los scriptoria monacales como crítica de las costumbres paganas. Sin duda, actualmente, la obra de Juvenal tan estudiada a lo largo de los siglos y que pudo ser invocado por Juan de la Cueva, se vuelve especialmente problemática en nuestra época del feminismo y del relativismo. No nos cabe duda que muchos lectores actuales, aun con marcado anacronismo, tildarían estas sátiras de elitistas, sexistas y xenófobas. El éxito de Juvenal, sin embargo, queda cristalizado en la fortuna de dos o tres clichés de intenso uso hasta el día de hoy: «panem et circenses» («pan y circo»), «sed qui custodiet ipsos custodes?» (¿quién guarda al guardián?), o bien, «mens sana in corpore sano».

Y hasta aquí, el elenco cuyo contenido he recordado de forma superficial y esquemática. Me ha parecido, no obstante, que era necesario hacerlo, ya que nuestro autor, al traer estos autores a la memoria, está procurando dos 
cosas: demostrar que los conoce y, en el caso de la comedia española, demostrar que los contraviene deliberadamente y no por ignorancia. Tampoco, por impericia, pero ésa es ya otra cuestión.

Desde luego, la inserción de la relación en la Epístola I, señala la importancia de la convención vigente en el Renacimiento, pero no la relevancia de estos autores ni seguramente en la vida cultural de su momento, ni, desde luego, en el Ejemplar.

\section{TEATRO ESPAÑOL}

Lo aquí recordado brevemente forma parte de la convención, pero la cuestión novedosa de la época, la existencia de una nueva poética del teatro español, que difiere de las adaptaciones de los clásicos, es clave en el Ejemplar poético, aunque se trate al final de la Epístola III. Juan de la Cueva, que ha empezado con el canon de los autores latinos para certificar su conocimiento, hace desfilar al final todavía a Ennio, Plauto, Medio, Accio, antes de mostrar el hecho de la transgresión de la unidad de estilo en la nueva comedia:

Que en cualquier popular comedia hay reyes,

y entre los reyes, el sayal grosero

con la misma igualdad que entre los bueyes.

(III, 502-504)

Y, tras estos versos (sinceramente) horribles, continúa ya «echándose la culpa» orgullosamente a sí mismo de haber reducido en un acto los cinco tradicionales y de haberlos dividido en jornadas. Insiste, además, en que tales atrevimientos, que no se hacen por desconocimiento, tampoco se derivan de la impericia, sino que se llevan a cabo por autores de altura:

Mas siendo dinos de mojar los labios

en el sacro licor aganipeo,

que enturbian Mebios y corrompen Babios.

(III, 517-519)

Hay que abrazar las novedades del «tiempo nuevo» y no quedarse anclado en el remoto Hesíodo («huyendo aquella edad del viejo Ascreo»). Fuera, pues, el corsé rígido de las unidades, especialmente la unidad de 
tiempo, «que forzaba/ a tratar tantas cosas diferentes/ en término en un día que se daba».

Es cierto que seguían las normas del teatro tradicional sus contertulios de Sevilla, los «sevillanos cómicos», Luis Vélez de Guevara, Gutierre de Cetina (probablemente el famoso madrigalista del que no nos ha llegado esta presunta producción teatral), Cózar y Fuentes, el «ingenioso Ortiz», el «austrífero Mejía», (don Pedro Mexía) y el «Menandro Bético», su maestro Mal Lara. Y otros muchos autores respetables:

Otros muchos que en esta estrecha vía obedeciendo al uso antiguo fueron en dar luz a la cómica poesía.

(III, 538-540)

Hay sí una comedia tradicional aceptada de buen grado por el público, que preveía un elenco convencional de personajes:

Un gabán, un pellico y un cayado;

un padre, una pastora, un mozo bobo, un siervo astuto y un leal criado.

(III, 556-558)

No obstante, Juan de la Cueva entiende que se trata de una fábula «sin ornato», «sin artificio» y «corta de argumentos». «Los ingenios fueron creciendo», «mejorando las artes» y fueron desechándose las reglas que, hasta el momento, se habían conservado reverentemente:

Tuvo fin esto, y como siempre fuesen

los ingenios creciendo y mejorando

las artes y las cosas se entendiesen

fueron las de aquel tiempo desechando.

(III, 562-565)

La posición de Juan de la Cueva es contundente. Los cambios de la comedia española no se derivan de la impericia ni de la irresponsabilidad, sino de una prudente adaptación a las nuevas realidades. No se trata de algo censurable, sino, en el otro extremo, es una realidad merecedora de alabanza. A diferencia de Lope de Vega, no otorga razón alguna a los contradictores. Al contrario: 
Esta mudanza fue de hombres prudentes

aplicando a las nuevas condiciones

nuevas cosas que son las convenientes.

(III, 568-570)

En la lectura lineal que venimos haciendo del pasaje, se introduce ahora una diatriba con el interlocutor que defiende el teatro antiguo y al que le parece bárbara e inadmisible la nueva comedia que ha sido defendida de la forma que acabamos de ver por el autor del Ejemplar poético en su calidad de representante de las nuevas formas.

Las objeciones del contradictor son, en opinión de Juan de la Cueva, solamente frutos de la inercia, de la extrañeza que produce todo aquello a lo que no estamos previamente acostumbrados. Si nos atenemos solamente a los resultados, podremos experimentar que son buenos, de manera que «con la verdad se templa su aspereza».

Juan de la Cueva llega a sugerir que, si pasa por encima de los prejuicios, su interlocutor descubrirá las insuficiencias de lo que viene practicando y terminará por abrazar el nuevo modelo:

Confesarás que fue cansada cosa cualquier comedia de la edad pasada, menos trabada y menos ingeniosa.

(III, 583-585)

Aunque Juan de la Cueva no quiere ser iconoclasta: dice explícitamente que los clásicos merecen perpetua alabanza y que sus temas y doctrinas son «excelentes»:

Del arte, del ingenio, de la ciencia en que abundaron con felice copia no trato, pues lo dice la experiencia.

(III. 595-597)

Esto no es obstáculo para que, dejando de lado las odiosas comparaciones de un autor singular con otro, afirme que la nueva poética de la comedia española es netamente mejor:

Mas la invención, la gracia y traza es propia

a la ingeniosa fábula de España,

no cual dicen los émulos impropia.

(III, 598-600). 
La verdadera traza de la comedia clásica no es, en su opinión, la que se limita a los moldes estrictos de los griegos y latinos, sino la de aquellos que los recrean con una nueva invención y gracia, que es la propia de la fábula en España, de manera que los verdaderos imitadores no serían los «émulos», sino los innovadores. La comedia española, en cuanto a la composición, es la que posee mayor número de enredos y de burlas jocosas y, en cuanto a los temas, tiene acreditadas historias, excelentes vidas monásticas y eficaces efectos de amor. Se trata de una superioridad que, según Juan de la Cueva, era admitida ya por los «sabios». y «prudentes». Claro que eso depende de a quienes se les atribuya estos calificativos. Desde el punto de la aceptación académica, sabemos que no existía tal reconocimiento unánime.

Admitido el principio, vuelve Juan de la Cueva a los consejos tradicionales y de sentido común que caracterizan el Ejemplar normalmente. Prescribe la coherencia:

Al viejo avaro envuelto en desventuras, al mancebo, rabiando de celoso, al juglar decir mofas y locuras. Al siervo sin lealtad, y cauteloso, a la dama amorosa y desabrida, y a con semblante alegre ya espantoso. (III, 625-630)

Sigue con «la tercera», «el lisonjero», «el rufián». Insiste una vez más en la pulcritud del verso y de la lengua y en la coherencia también estilística. Considera que las normas que permanecen no están sujetas a la libre determinación del poeta, sino que es necesario seguirlas en todas las comedias. Hay que atender a las reglas («arte») antes que al capricho del autor, por más que transgredir la norma pueda resultar seductor.

Como resumen de su posición, trae de nuevo a colación a su maestro Mal Lara como ejemplo de buen hacer:

El maestro Mal Lara fue loado

porque en alguna cosa alteró el uso

antiguo, con el nuestro conformado.

En el teatro mil tragedias puso

con que dio nueva luz a la rudeza

della apartando el término confuso.

(III, 697-702) 
Más allá de estas y otras varias apostillas, lo importante a nuestro propósito es insistir en que Juan de la Cueva afronta el debate de la comedia española sin la menor concesión a sus detractores. Como Lope de Vega en el Arte Nuevo de Hacer Comedias, intenta mostrar que conoce a los grandes maestros de la antigüedad, según hemos visto, pero dice que no hay que seguirlos servilmente, porque los tiempos cambian, las necesidades también y los modos de imitación mejoran. La transgresión de las unidades no es consecuencia de la ignorancia ni de la ineptitud, sino, al contrario, de la madurez del arte. Su posición es literalmente contraria a la del Arte Nuevo cuyas disculpas llevaron a Menéndez Pelayo (1890) a la conocida diatriba antilopesca: «lamentable palinodia que apenas es menester citar porque vive en la memoria de todos, llama bárbaro de mil modos al pueblo que, teniendo razón contra él, se obstinaba en aplaudirle, y se llama bárbaro a sí mismo, y hace como que se ruboriza de sus triunfos por contemplación a los doctos refinados y discretos, y se disculpa con la dura ley de la necesidad, como si hubiese prostituido el arte a los caprichos del vulgo; y hace alardes pedantescos de tener en la uña la poética de Aristóteles y sus comentadores...j Triste y lastimoso espectáculo en el mayor poeta que España ha producido! ¡Cuánto le cuesta al verdadero genio hacerse perdonar su gloria!».

El caso es que tampoco coincide con la otra instancia que presenta Lope para explicar lo inexplicable en su «texto indecidible» (Garrido Gallardo, 2010). Según Menéndez Pidal (1935: 102-103), el verso perder el respeto a Aristóteles es la primera gran afirmación del Fénix de los ingenios, pues alumbra Lope una comedia que, al mezclar lo noble y lo plebeyo, lo festivo y lo grave, habría de ser condenada unánimemente por todos los tratadistas, tanto de Italia como de España, quienes la calificarían de «monstruo hermafrodita». Sin embargo, tomando Lope como bandera la injuriosa denominación, hace valer que el «vulgo» (el que no sabe de extravagantes reglas académicas) deba dictar las nuevas leyes del arte, «la vil quimera de este monstruo cómico». Y es más, implícitamente, denunciará como algo monstruoso la tragedia pura, pues viene a decir que la reprobada mezcla de Séneca y Terencio es lo verdaderamente conforme con la belleza natural.

Nada de nada. Según Juan de la Cueva, la comedia española es superior a sus antecedentes clásicos por las razones que ha expuesto, pero ni tiene por qué descalificar la comedia clásica, ni tiene por qué sentirse culpable, ni echa la culpa al «vulgo» de una iniciativa que es razonable y digna de elogio. 


\section{OTRA POÉTICA}

La poética teatral de Juan de la Cueva expuesta al final de su obra presupone la opción de la excelencia y el decoro en el equilibrio entre ingenium y ars de los que nos hablaba al principio. Hay a lo largo del texto desarrollos de casi todas las cuestiones que cabía esperar y defiende a sangre y fuego la comedia española, según hemos visto. Pero hay algo que hemos saltado, el final de la Epístola I, donde nos cuenta una extraña anécdota y nos propone un principio insólito.

Nos dice que conoció a un poeta aplicado en varios argumentos y, en especial, a los que cultivó Ennio (serían los temas de sus tragedias inspiradas en Eurípides o los hechos de su Historia de Roma). Sucedió que le faltaba ingenium y resultó ser un poeta, como resume Fujioika (2010:82), sin unidad de estilo, sin vigor figurativo, sin latinitas.

Sin unidad de estilo:

Que las cosas comunes sin alteza

en lugares sublimes colocaba,

y las sublimes las ponía en bajeza.

Que en los sagrados épicos usaba

concetos ordinarios, ignorando

la majestad que en ellos demandaba.

(I, 385-390)

Sin vigor figurativo:

Que no les iba a sus escritos dando

hermosura con flores y figuras,

que en variedad los fuesen esmaltando.

(I, 391-393).

Sin latinitas:

Que las dicciones ásperas y duras

no supo corregir, y usando de ellas

las nuevas ofuscó y dañó las puras.

(I, 394-396) 
Dentro de la convención renacentista, se nos presenta el dicho autor elevando una plegaria al dios Febo, astro inspirador, y le pregunta si, así las cosas, debe abandonar el «cómico y trágico argumento». Cómico, es decir, la «imitación de hombres inferiores pero no en toda la extensión de vicio, sino que lo risible es parte de lo feo. Pues lo risible es un defecto y una fealdad que no causa dolor ni ruina» (Aristóteles, Poética 1449. ${ }^{a}$ ). Trágico, o sea, «una acción esforzada y completa, de cierta amplitud, en lenguaje sazonado, separada cada una de las especies en las distintas partes, actuando los personajes, y no mediante relato, y que mediante compasión y temor lleva a cabo la purgación de tales afecciones» (1449b).

«¿Debo o no desvelarme en las sátiras libres? O sea, ayunas de conveniente silencio, enfrentadas con la vergüenza que atestiguan con los ojos una cierta perversión de la mente, derramadas por la boca en una desaforada palabrería».

«¿Dejo de hacer notorio el sentimiento (...) en élegos llorosos, y en líricos suaves mi tormento?» $\mathrm{O}$ sea, se pregunta por si debe cultivar los hexámetros u otro metro lírico. Y más: ¿debe consagrarse a la épica, al verso heroico, al ámbito del dios guerrero Marte, o no? Tampoco parece que se le ha dado bien a nuestro autor ejemplar el género épico o la formulación de algún acontecimiento con el propósito de abarcar una serie total de sucesos. A nuestro autor no hay por donde cogerlo y falla una y otra vez en los preceptos de la Rueda de Virgilio de la que se deriva la necesidad de que el estilo gravis se reserve para la tragedia, el humilis para la comedia y el estilo elegíaco para las desgracias (A. Faral, 1924: 153).

El poeta en cuestión no dispone de los recursos de todo verdadero creador. Evidentemente carece de la capacidad de la inventio cuya primacía se proclama en el Ejemplar poético según hemos ya visto. También falla en la expresión y, por supuesto, en la imprescindible adecuación de forma y fondo, donde se decide la calidad de la obra.

La inventio poética va ligada a la inspiración y, por tanto, más que una tarea de hallazgo de ideas que van a ser distribuidas a lo largo del poema, se trata de una aptitud para recibir un legado que trasciende al propio poeta. Por eso, el Ejemplar poético nos dice:

$Y$ tome solamente los sujetos

a que su ingenio más aficionare

sin que en ellos violente los efectos.

(I, 340-342) 
Juan de la Cueva otorga una primacía indiscutible al ingenio, entendido como capacidad espontánea, como inspiración. Veamos cómo insiste:

\section{El ingenio da fuerza a la elegancia \\ es la fuente, y el alma al inventiva, y sin él, todo hace disonancia.}

(I, 346-348).

Ilustra esta tesis con la comparación del caballo que se resiste a ser gobernado, por más que el jinete se empeñe, pero que cuando se le muda de puesto y se le sitúa en el ajustado, realiza cuanto no ha sido posible que realizara con apremio. Lo mismo, dice Juan de la Cueva, acudiendo una vez más a la mitología, ocurre en el que hizo el sueño a la viuda y a Venus en el jardín tan deshonesto.

El que tuvo siempre una musa «tosca y dura», cuando no fue lasciva, logró, sin embargo, que fuera fácil y aguda en siendo obscena. Otra musa, en cambio, siguiendo los pasos de ésta, nunca dejó de ser molesta y confusa, excepto en las pullas, en las que fue admirable y produjo versos extremados.

Juan de la Cueva concreta la posibilidad de esas capacidades para cada uno de los grandes géneros y, simplificadamente, hace coincidir los géneros con los temas, lo cual no es cierto del todo, aunque el fondo temático sea uno de los elementos que configuran la calificación genérica en la acertada tradición aristotélica. Naturalmente, la acomodación entre contenido y expresión se produce de distinto modo en cada uno de los géneros. Pues bien, el poeta del ejemplo se encuentra con que él mismo no logra acertar en esto y todo el público lo deplora y afea su poca capacidad. ¿Qué hacer en este callejón sin salida?

Invoca de nuevo a Apolo/Febo:

Acude a este sufragáneo tuyo, Acude, Apolo, a la infelice suerte

en que en tan triste deshonor concluyo.

(I, 445-447)

Y cae en un profundo sueño durante el cual se obra el prodigio: despierta adornado con el anillo de Giges, ha adquirido una lucidez nueva que le manifiesta la solución de su irresoluble inquietud. 
El ingenio que supe mal regillo,

arrebatado de él, cautivo y ciego

por tantos disparates, di en seguillo;

ahora que a la sacra luz me llego,

estas obras que hice sin seguilla

contra mi natural, mueran en fuegos.

(I, 481-486)

Pero, al volver al sentido común, no abandonó su actividad «literaria», sino que se consagró a aquello para lo que tenía capacidad, olvidándose de todo lo demás. Nada de imitar grandes obras de la tradición grecolatina, de manera rígida o con transformación innovadora, nada de querer introducirse en el canon de los poetas que se citan en el Ejemplar con elogio. Sí, en cambio, aceptar su «musa obscena», su capacidad para las pullas:

Dio en hacer coplas de plebeya gente

sin majestad heroica ni artificio,

en que su natural era ecelente.

(I, 502-504)

No abandonó su actividad «literaria». O sea, admite una noción extendida de lo literario que cubre productos que no se llamarían propiamente «poesía» en el siglo XVII. Admite que existen autores que no tienen capacidad para abordar los temas (géneros) que cultivan los autores canónicos, pero sí pueden consagrarse a una producción que tiene demanda en la sociedad.

La poética enseña preceptos para la calidad que disciernen entre las obras literarias y las que no alcanzan esa dignidad. Normalmente se ha considerado que estas segundas constituyen o una obra fallida o una concesión al vulgo ignorante. Resulta insólita, en cambio, esta toma de posición que las prevé como resultado de una opción deliberada, de algo con entidad propia. No es solamente que en el continuum, que lleva desde el extremo literario hasta el que no lo es, haya zonas fronterizas, no es que alguien se ponga a crear y no le «salga», es que se debe prever una actividad de entretenimiento y diversión para la que hay autores específicamente dotados y que tiene un público dispuesto. He aquí a Juan de la Cueva, creador de la poética subliteraria.

$\mathrm{Al}$ presunto autor de la anécdota, toda la «alta literatura» lo volvía confuso y, por eso, optó por apartarse de ella y elegir un tema absolutamente aje- 
no a los que caracterizaban cada uno de los géneros. Y que no deja de ser sorprendente: la Tarasca (Cf. Holman and Valen, 1975).

Perteneciente quizás a una leyenda medieval con orígenes en la mitología pagana, la Tarasca es un monstruo cuya concreción más cercana parece de origen provenzal. Se trata de un dragón de seis cortas patas parecidas a la de un oso, con un torso de buey, un caparazón de tortuga y una escamosa cola que terminaba en el aguijón de un escorpión. Su cabeza es la de un león con orejas de caballo y expresión horripilante.

El rey de Tarascón había combatido sin éxito a la Tarasca a pesar de que puso en acción todos los medios de que disponía, pero Santa Marta detuvo a la bestia con sus oraciones y dominándola la paseó por la ciudad como un animal doméstico. Los habitantes de Tarascón atacaron a la bestia entonces y murió sin ofrecer resistencia.

En España aparece en las procesiones de Corpus Christi de Granada y de Valencia y, con diversos revestimientos, en otras ciudades de Cataluña y de Galicia. En Toledo sale en la víspera de la procesión acompañada de los tradicionales gigantes y cabezudos, aunque la recuperación de este simbolismo relacionado con la muerte y el pecado es muy reciente en este último caso.

El texto del Ejemplar poético dice lo siguiente:
Libre del Caos que le traía confuso, cantó en heroico plectro la ecelencia de la Tarasca, con ingenio infuso. Cantó su natural y descendencia, el origen, la causa, el fundamento de hacer en Sevilla su asistencia. (I, 517-522)

Como se sabe, la fiesta de Corpus Christi reviste un especial esplendor en Sevilla y, sin duda, la Tarasca estaba también aclimatada en la procesión de esta capital andaluza.

En definitiva, lo que el Ejemplar poético concluye es que si alguien no tiene capacidad para abordar la creación de cumbres estéticas, como las que señala en su canon latino, deberá abandonar los grandes géneros y acomodarse a temáticas para la que esté capacitado, que produzcan solaz y entretenimiento. Así, adecuándose a las propias capacidades, se obtendrán buenos resultados; en tanto que intentando estar por encima de las propias 
posibilidades, se está abocado al fracaso. Uno debe optar por ser autor subliterario.

Ejemplo de lo dicho sería en el mundo clásico el caso de Querilo, poeta de Alejandro Magno que, según Juan de la Cueva, mereció poca estimación precisamente por no seguir estas indicaciones. Se lanzó a cantar la épica gloriosa de la victoria de Atenas contra Jerges y, como no tenía aliento para ello, cayó en el descrédito:

Tenga el poeta en la memoria impreso

esto, y con este ejemplo no se aparte

de lo que tengo del ingenio expreso,

quél es la forma y la materia, el Arte.

(I, 541-544)

Lo que Juan de la Cueva receta es un cambio en la imitación, noción nuclear de la poética del Renacimiento (Cf. García Galiano, 1992) que vincula los géneros a los objetos imitados y a las formas de imitar. «Imitación» recubre contenidos distintos. En su versión latina (imitatio), se refiere generalmente a la posibilidad de que las lenguas vernáculas imiten a las lenguas clásicas en la medida en que desean ser un vehículo expresivo con la misma categoría que se le reconoce al griego o al latín. Al lado de esta acepción, es también muy frecuente otra de carácter estrictamente literario: los autores que se consideran modélicos tanto en la propia época como en la antigüedad griega y romana deben ser imitados y la cuestión estriba en cómo lograr tal imitación en cuanto a los versos, los temas o los personajes. Y no sólo se refiere esto a la antigüedad clásica. Petrarca era el modelo de todos los sonetos, y escribir al estilo de Petrarca era escribir sonetos de calidad. Estas dos acepciones de la palabra imitatio (imitación) son sustancialmente distintas del empleo que también encontramos como clave teórica de la Poética aristotélica (mímesis). Ésta significa creación o recreación, lo que, en el Renacimiento, pasó a entenderse como una exigencia, a saber, la de que la literatura tiene que imitar la naturaleza, tomando «naturaleza» en sentido muy amplio: lo natural, lo humano, lo cultural.

Pero volviendo a la imitación de modelos, esta poética se fundamentaba en la convicción de que si un autor ha triunfado en su creación, bastará imitar con exactitud lo que este artista hizo para conseguir también un resultado logrado. Juan de la Cueva afronta el problema de la falta de límites entre imitación original y simple plagio. Toda la cuestión de la intertextualidad lite- 
raria aparece aquí. Imitación, ¿de qué? ¿Del tono literario? ¿Del registro lingüístico? ¿De las historias y contenidos?

El caso es que el Ejemplar poético avala la imitación de los autores clásicos («sermón romano»):

La imitación en tiempo conveniente

es lícita, y licencia permitida

al ingenio más alto y excelente.

(II, 427-429)

Por supuesto, descalifica sin ambages el plagio:

Del hurtar, sin que usemos de razones

que de nuevo lo aclaren, están claras

del uso dél las bajas condiciones.

(II,.436-438)

Vinculado a ese empeñarse en lo imposible de que ha hablado, vuelve a subrayar la contradicción que supone el intento de conseguir gloria literaria mediante un procedimiento que lo que logra es descalificar a su autor.

Por razones de sistemática, como tercer modo de posible imitación, incluye la traducción. Se ve que Juan de la Cueva es muy entusiasta de esta labor:

Es el modo tercero la divina

tradución, tan difícil cuan gloriosa

al que observa el decoro a su doctrina.

Su ley es inviolable y religiosa, tratada con lealtad y verdad pura que ni pueden quitar ni añadir cosa. (II, 445-450)

Admite luego una atenuante a la exigencia de no quitar ni poner nada, ya que podría el traductor apartarse de la literalidad si, con ello, se mejora el original sin contravenirlo. También se permite pasar en la traducción de una codificación rítmica a otra: lo importante es mantener la sustancia del «concepto», del «número»y la «sentencia».

No nos dispensará Juan de la Cueva de certificarnos con su repaso que conoce las poéticas. Veamos cuáles. 
En primer lugar, Poetices libri septem de Julio Cesare Escalígero, obra publicada en 1571 y reimpresa varias veces. Se trata de un original de contenido fuertemente lógico, dividido en siete libros: el primero, «Historicus», examina el origen de los poemas y trata de la distinción entre poesía, historia y ciencia, reformulando la conocida doctrina de Aristóteles, admitiendo la posible imitación de lo inexistente, lo cual no querría decir ficción, sino una cierta capacidad de creación que está en poder del poeta mismo. El libro segundo, «Hile», trata de los versos, sus elementos, metros y ritmos. El tercero, «Idea», trata del poema y las figuras retóricas. El cuarto, «Parescebe», trata de los caracteres y la expresión. El quinto, «Criticus», compara a Virgilio con Homero y otorga la superioridad al poeta latino. El sexto, «Hipercriticus», es una historia de la poesía latina. El séptimo y último, «Epinomis», contiene de nuevo conceptos generales y algunas normas sobre la tragedia.

Viene luego el botánico Bartolomeo Maranta, cuya obra principal, a nuestro propósito, son los cinco volúmenes de las Lucullianae quaestiones (1574). Uno de los intereses de Maranta fue la cuestión de lo «maravilloso», que entiende como lo sin precedente, nuevo y más allá de lo esperado.

A continuación, Pontano y Marco Girolamo Vida. Este segundo es autor de los tres libros De arte poética, publicados entre 1522 y 1527 . Humanista italiano, que escribió su obra en latín, aparece repetidamente citado como referencia (por ejemplo, en los libros de retórica de Benito Arias Montano) y no es extraño, por tanto, su presencia aquí. En cuanto a Giovanni Pontano, otro humanista, algo anterior en el tiempo, era muy conocido también como descubridor del Comentario de Donato al poeta Virgilio.

La cita que no podía faltar era la de Minturno («cual el sol del día») que formula la nueva estética basada más inequívocamente en la autoridad de Aristóteles (C. Bobes, 1995, 1998). Se trata de la obra L'arte poetica del signore Antonio Minturno, nella quale si contengono i precetti Heroici, Tragici, Comici, Satyrici e d'ogni altra poesia: con la dottrina de'sonetti, canzoni et ogni sorte di Rime Thoscane, dove s'insegna il modo che tenne il Petrarca nelle sue opere. Et si dichiara a'suoi luoghi tutto quel, che da Aristotele, Horatio, et altri autori Greci e Latini, é stato escritto por ammaestramento di Poeti (1564). Esta obra supone un giro de Minturno desde las posiciones más cercanas a Platón y a Cicerón que había mantenido en su obra De Poeta (1559). Ahora representa la posición aristotélica rigurosa que se había propiciado en el clima del Concilio de Trento.

Afirma Minturno que la poesía es reina de todas las ciencias y madre de todas, porque todas de ella se derivan. Su fin es ser recreo y servir de des- 
canso a los ánimos cansados. Recoge en su obra unas supuestas conversaciones que mantuvo con Vespasiano Gonzaga y otros militares en el año 1557, al término de la guerra entre Pablo IV y el duque de Alba, en casa de la princesa Isabel Colonna, madre de Vespasiano. La técnica dialogal es semejante a otras de la época como la que vemos, por ejemplo, en la Philosophía antigua poética del Pinciano. En forma dialogal, las teorías se exponen de modo sistemático con abundancia de ejemplos de la poesía clásica e italiana. Cada uno de los tres primeros libros se dedica a un género distinto. En el primero se nos enseña que la poesía es imitación y que, por consiguiente, ha de considerar tres cosas: qué se imita, con qué se imita y de qué manera se imita. Como hemos dicho, reconoce a Aristóteles la más alta autoridad. En cuanto a la técnica de diálogo, el interlocutor va preguntando y Minturno contesta a medida que se le formulan las preguntas (Cf. Rico Verdú, 1998).

Por lo demás, Juan de la Cueva nos dice que Horacio tiene uno de los primeros puestos en la doctrina literaria. Igualmente Aristóteles es propuesto como número uno sin posible apelación:

Acuden todos a colmar sus vasos

al oceano sacro de Stagira

donde se afirman los dudosos pasos,

se eterniza la trompa y tierna lira.

(II, 556-559)

Todo esto lo conoce, pero no tiene nada que ver con la aportación que ponderamos. Todo el cotexto, que he glosado levemente, de los pasajes que nos interesan y todos los demás asuntos del Ejemplar poético no mencionados no pasan de transmitir convenciones o incluir consejos bien intencionados, pero ayunos de mayor interés. La posibilidad, razones y oportunidad de una poética subliteraria, que emerge en medio de tanto convencionalismo, es, en cambio, una aportación original que era preciso poner de relieve y subrayar.

\section{REFERENCIAS BIBLIOGRÁFICAS}

ARISTÓTELES (1974). Poética. Traducción de Valentín García Yebra. Madrid: Gredos.

- (1985). Retórica. Traducción de Antonio Tovar. Madrid: Centro de Estudios Constitucionales. 
BOBES NAVES, M.C. (1995). Historia de la teoría literaria I: la antigüedad grecolatina. Madrid: Gredos.

- (1998). Historia de la teoría literaria II. Transmisores. Edad Media. Poéticas clasicistas. Madrid: Gredos.

DE LA CUEVA, J. (1606). Ejemplar poético. Edición de Francisco A. de Icaza. Madrid: Espasa-Calpe, 1973.

CURTIUS, E. R. (1948). Literatura europea y Edad Media latina. Traducción de Margit Frenk. México: Fondo Cultura Económica, 1981.

DÍAZ RENGIFO, J. (1592). Arte poética española. Madrid: Dirección General de Patrimonio Artístico y Cultural, 1977 (Facsímil).

FARAL, A. (1924). Les arts poétiques du moyen âge. Paris: Champion, 1982.

FUJIOKA, T. (2010), El «Ejemplar poético» de Juan de la Cueva y la Preceptiva poética española de principios del siglo XVII. Curso de Alta Especialización en Filología Hispánica. CCHS/CSIC (Tesis de magíster inédita).

GARCÍA BERRIO, A. (1980). Formación de la teoría literaria moderna 2. Teoría poética del Siglo de Oro. Murcia: Universidad de Murcia.

GARCÍA GALIANO, Á. (1992). La Imitación poética en el Renacimiento. Kassel: U. de Comillas/Reichenberger.

GARRIDO GALLARDO, M. Á. (2010). «El Arte nuevo de hacer comedias, texto indecidible». Rilce 27,1, 103-118.

GARRIDO GALLARDO, M. Á. (ed.) (2004). Retóricas españolas del siglo XVI escritas en latín. Edición digital. Madrid: Fundación Ignacio Larramendi/ CSIC.

GARRIDO GALLARDO, M. Á. LUJÁN, A. L. y ALBURQUERQUE, L. (2007), «Spanish latin Rhetoric of 16th Century». En Respublica litteraria in action, A. Skolimowska (ed.), 47-84. Warsaw: OBTA.

GARRIDO GALLARDO, M. Á.; LUJÁN, A,; ALBURQUERQUE, L. y MARTÍNEZ, M. A. (1998): «Retóricas españolas del siglo XVI en la Biblioteca Nacional de Madrid». Revista de Filología Española, LXXVIII, 3-4, 327-351.

HOLMAN, F. and VALEN, N. (1975). The Drac: French Tales od Dragons and Demons. Ilustraciones de S. Walker. New York: Scribner's Sons. 
HORACIO FLACO, Q. (1997). Epístola a los Pisones. En Poéticas: Aristóteles, Horacio, Boileau. Traducción de Aníbal González Pérez. Sevilla: Alfar.

JIMÉNEZ PATÓN, B. (1604). Elocuencia española en arte. Barcelona: Puvill, 1993.

LÓPEZ PINCIANO, A. (1596). Obras completas, I. Philosophía antigua poética. Edición de José Rico Verdú. Madrid: Fundación José Antonio de Castro, 1998.

MENÉNDEZ PELAYO, M. (1883-1889). Historia de las ideas estéticas en España: Madrid: CSIC, 1994, 2 vols.

- (1885). Horacio en España. En Obras completas, Menéndez Pelayo Digital. Madrid: Fundación Histórica Tavera, 1999.

- (1890-1902). Estudios sobre el teatro de Lope de Vega. En Obras completas, Menéndez Pelayo digital. Madrid: Fundación Histórica Tavera, 1999.

MENÉNDEZ PIDAL, R. (1935). «Lope de Vega, el Arte Nuevo y la nueva biografía». Revista de Filología Española, XXII, 1-2, 1935, 337-398. También en Lope de Vega. El Teatro I. Edición de Antonio Sánchez Romeralo. Madrid: Taurus, 1989, 89-144 (Col. «Persiles». Serie «El escritor y la Crítica»).

MINTURNO, S. (1564). Arte poética. Traducción de M. C. Bobes. Madrid: Arco / Libros - UNED, 2009.

NORTON, Glyn P. (ed.) (1999). The Cambridge history of literary criticism. Cambridge: Cambridge University Press.

PRIETO, Antonio (1984). La poesía española del siglo XVI. I. Andáis tras mis escritos. Madrid: Cátedra. II. Aquel valor que respetó el olvido. Madrid: Cátedra.

QUINTILIANO, Marco Fabio (1997). Sobre la formación del orador. Institutionis oratoriae. Traducción de Alfonso Ortega Carmona. Salamanca: Universidad Pontificia, 5 vols.

RICO VERDÚ, J. (1998). «Introducción a la Philosophía antigua poética.» En El Pinciano, Obras completas, I: Philosophía antigua poética, IX-XXI. Madrid: Fundación José Antonio de Castro.

SALINAS, M. de (1541). Rhetorica en lengua castellana. Napoli: L'Orientale Editrice, 1999. 
SÁNCHEZ DE LIMA, M. (1580). El arte poética en romance castellano. Edición de Rafael de Balbín Lucas. Madrid: CSIC (I. «Nicolás Antonio» de Bibliografía), 1944.

SHEPARD, S. (1970) El Pinciano y las teorías literarias del Siglo de Oro. Madrid: Gredos.

SMITH, P. J. (1985). «The Rhetoric of Presence in Poets and Critics of Golden Age Lyric: Garcilaso, Herrera, Gongora». Modern Language Notes 100.2, 223-246.

SPINGARN, J. E. (1963). A History of Literary Criticism in the Renaissance. New York: Columbia University Press, 2. ${ }^{\mathrm{a}}$ ed. ${ }^{\circ}$

TERRY, A. (1993). Seventeenth-Century Spanish Poetry: The Power of Artifice. Cambridge: Cambridge University Press.

VEGA, Lope de (1609). Arte Nuevo de hacer comedias en este tiempo, dirigido a la Academia de Madrid. Edición anotada y prologada por Felipe Pedraza. Madrid: Sociedad Estatal de Conmemoraciones Culturales, 2009.

VILANOVA, A. (1949). «Preceptistas españoles de los siglos XVI y XVII». En Historia general de las literaturas hispánicas, Guillermo Díaz-Plaja (ed.), 566-692. Barcelona: Barna.

WALBERG, F. Gustav. Emanuel (1961). Juan de la Cueva et son «Exemplar poético». Lund: Hakan Ohlsson.

WEINBERG, B. (1961). A History of Literary Criticism in the Italian Renaisssance. Chicago: University of Chicago Press.

- (2003). Estudios de poética clasicista: Robortello, Escalígero, Minturno Castelvetro. Edición, selección y prólogo de Javier García Rodríguez. Madrid: Arco / Libros.

Recibido el 26 de junio de 2011.

Aceptado el 22 de septiembre de 2011. 